\title{
O DISCURSO DE DIVULGAÇÃO CIENTÍFICA NA REVISTA SUPERINTERESSANTE: 0 FIM DO MUNDO É PROFECIA OU REALIDADE?
}

\author{
THE SCIENTIFIC POPULARIZATION DISCOURSE IN THE SUPERINTERESSANTE
}

MAGAZINE: IS THE END OF THE WORLD PROPHECY FACT OR FICTION?

\author{
Maíra Ferreira Sant'Ana \\ Universidade Federal de Viçosa \\ Cristiane Cataldi dos Santos Paes \\ Universidade Federal de Viçosa
}

\begin{abstract}
RESUMO: Este artigo pretende analisar o tratamento linguístico-discursivo conferido às informações sobre o Fim do Mundo referentes a uma reportagem publicada na revista Superinteressante, edição especial de novembro de 2012, durante a polêmica suscitada pelo Calendário Maia. Para isso, buscou-se descrever e analisar como ocorre o processo de recontextualização do conhecimento científico em textos de divulgação científica por meio dos procedimentos linguístico-discursivos de expansão, redução e variação e das estratégias divulgativas. Ao final da análise, chegou-se à conclusão de que a situação de comunicação é norteadora do discurso veiculado na reportagem. Verificou-se também que foram utilizadas várias estratégias divulgativas direcionadas para um público jovem. Percebeu-se que a revista informa e, como estratégia discursiva, deixa o leitor curioso e motivado em ler sobre o assunto em questão. O procedimento linguístico-discursivo mais recorrente na reportagem foi a expansão e a estratégia divulgativa mais utilizada foi a explicação.
\end{abstract}

PALAVRAS-CHAVE: Recontextualização; Procedimento linguístico-discursivo; Estratégia divulgativa.

ABSTRACT: In this study, we looked at the linguistic and discursive treatments given to the questions of the End of the World in one report published in the popular science magazine Superinteressante, issued November 2012, at the height of the polemics surrounding the Mayan Calendar. We described and analyzed the process of reelaboration of the scientific information by means of the linguistic-discursive strategies of expansion, reduction and variation, along with publishing strategies. We concluded that the communicative situation leads the discourse in the report and observed that publishing strategies were used to address and interact with young readers. We also observed that the magazine informs and hooks its readers by letting them concerned and curious. The linguistic-discursive strategy most used was the expansion. The publishing strategy most frequent was the explanation.

KEYWORDS: Reelaboration; Linguistic-discursive procedure; Strategy of popularization.

\section{INTRODUÇÃO}

Assuntos concernentes à origem e ao fim do mundo sempre despertaram o interesse e a curiosidade de diversas pessoas, as quais recorrem muitas vezes à ciência, à religião e/ou à filosofia para encontrar respostas às suas indagações. Essas questões suscitam, em geral, um amplo debate, no qual as formas de pensamento supracitadas 


\section{Revista do SELL}

v. 6 , no. 3

ISSN: $1983-3873$

defendem distintas concepções; e foram muitas as tentativas, em diferentes épocas, para descobrir como o mundo surgiu e como terminará. No ano de 2012, essa temática gerou grande expectativa nas pessoas, uma vez que algumas acreditaram que no dia 21 de dezembro de 2012 aconteceria o Apocalipse Maia, o que causou grande polêmica em todo o mundo. Em função dessa profecia, esse assunto deixou de fazer parte apenas de especulações científicas e virou notícia, causando muita discussão, principalmente nos meios de comunicação.

A Civilização Maia criou vários calendários, todos cíclicos, os quais têm por base um sistema de contagem vigesimal. O baktun, que consiste em uma longa divisão de tempo, corresponde a 144 mil dias, o equivalente a 394,26 anos. O piktun está acima do baktun, e corresponde a 20 baktuns - 7885,2 anos. A convicção do Fim do Mundo tem por base o fim do $13^{\circ}$ baktun, que seria no dia 21 de dezembro de 2012, quando o Calendário Maia é zerado. Contudo, de acordo com alguns pesquisadores, essa crença diz respeito a uma interpretação equivocada dos ciclos do Calendário Maia, uma vez que o novo piktun se iniciaria quando se chegasse ao $13^{\circ}$ baktun, ou seja, o mundo não acabaria no período previsto. Seria apenas o fim de um ciclo e o começo de outro, próprio de culturas que acreditam em um tempo circular, diferentemente do calendário das civilizações modernas que é linear, havendo um começo e um fim.

A partir de toda a especulação sobre o Fim do Mundo esperado para ocorrer em 21 de dezembro de 2012, de acordo com algumas interpretações do Calendário Maia, surgiu o interesse em analisar como esse tema é divulgado na mídia impressa brasileira, a fim de perceber como ela difunde essas informações, já que os meios de comunicação, dentre outras funções, atuam como mediadores da informação científica, popularizando, mesmo que motivados por interesses próprios, o discurso científico.

Tendo, destarte, como foco a divulgação da ciência na mídia impressa, o presente artigo tem por objetivo analisar, por meio dos pressupostos teórico-metodológicos da Análise do Discurso da Divulgação Científica (CALSAMIGLIA, 1997, 2003; CALSAMIGLIA et al. 2001; CATALDI, 2003, 2007a e b, 2008, 2011; CASSANY et al. 2000; FERRERO, 2011; VAN DIJK, 2011), a abordagem linguístico-discursiva conferida às informações que foram veiculadas sobre o tema Fim do Mundo em uma reportagem contida na revista Superinteressante, na edição especial (311-A) de novembro de 2012. A escolha dessa mídia se deve ao fato de ser uma importante referência nacional no âmbito 
da divulgação científica, tendo, dessa forma, grande representatividade na difusão de informações sobre ciência.

Partindo do pressuposto de que os meios de comunicação são a principal fonte de informação sobre C \& T (Ciência e Tecnologia) disponível ao grande público, o presente estudo realiza uma análise linguístico-discursiva dos procedimentos utilizados no processo de divulgação científica, em termos de reformulação e recontextualização, sobre uma temática que suscita muita polêmica na sociedade - o Fim do Mundo - abordada na revista Superinteressante, em novembro de 2012.

\section{O PROCESSO DE RECONTEXTUALIZAÇÃO DA INFORMAÇÃO SOBRE CIÊNCIA COMO PRÁTICA DISCURSIVA}

A Análise do Discurso, conforme Cataldi (2007a), é um campo de estudo interdisciplinar que se encontra em crescimento e tem como interesse identificar, descrever e analisar a linguagem em uso. Assim, com base no aporte teórico e metodológico da Análise do Discurso, os textos, como elementos de análise, devem ser estudados a partir de seu contexto real de aparição, segundo os propósitos e as finalidades de cada situação comunicativa.

Calsamiglia (1997) destaca que a Análise do Discurso intenciona estudar os textos - orais e escritos - como produto do uso linguístico em situações concretas, nas quais há interação entre falantes e ouvintes, a partir de uma intencionalidade. Assume-se esse posicionamento porque, segundo essa autora, o meio influencia e condiciona o texto, ou seja, o contexto é fundamental para se compreender o texto. Van Dijk (2011, p. 22), define discurso como "um 'texto em contexto"'. Esse teórico também defende que é importante entender o significado dos contextos, pois eles explicam o motivo dos discursos serem distintos.

Nessa perspectiva, a Análise do Discurso da Divulgação Científica coloca em evidência um discurso particular que existe para divulgar conhecimentos específicos, podendo estar imbricado de interesses diversos, já que se trata de um discurso que decorre de distintas transformações, tanto relacionadas às suas condições e modos de produção quanto a seus propósitos comunicativos. Conforme Cassany et al. (2000, p. 77), "como qualquer outra forma discursiva, a divulgação não é uma prática objetiva, neutra ou desvinculada de pessoas e interesses; pelo contrário, é o resultado da negociação entre 


\section{Revista do SELL}

v. 6 , no. 3

ISSN: $1983-3873$

seus interlocutores ${ }^{1 "}$. Desse modo, os agentes do processo de divulgação do conhecimento científico, ao interferirem, por meio do processo de reformulação, na formação de opinião do leitor de mídias de divulgação científica, possibilitam uma situação comunicativa muitas vezes tendenciosa e com evidências do posicionamento editorial do veículo de comunicação.

Ciapuscio (1997) destaca que por meio da definição do termo "divulgar" percebe-se a existência de algo prévio, que precisa ser comunicado e que se supõe desconhecido, possuindo determinado nível de complexidade para seu novo público. Essa autora revela que, no caso da divulgação da ciência, trata-se de divulgar um conhecimento específico sobre um determinado campo do saber para leitores que possuem um conhecimento variado a respeito do tema. Ainda segundo essa autora, o propósito comunicativo das notícias de divulgação científica é duplo: proporcionar informação procedente do âmbito científico e persuadir acerca da importância e utilidade do conhecimento enfocado.

Segundo Calsamiglia, Bonilla, Cassany, López e Martí (2001), o processo de recontextualização do conhecimento científico é compreendido como uma "re-criação" desse tipo de conhecimento para cada público específico. Dessa maneira, o divulgador científico e/ou o jornalista tem acesso ao discurso científico e o transforma, por meio do processo de recontextualização, no discurso de divulgação. De fato, esse exercício divulgador requer não somente o uso de uma forma discursiva apropriada à nova situação comunicativa, mas também a utilização de estratégias que possibilitem o entendimento das informações científicas por parte de um público leitor distinto.

Cataldi (2007a) ressalta que essa prática discursiva não consiste simplesmente em se fazer um resumo ou na redução aleatória de dados científicos, mas revela uma habilidade em selecionar, reorganizar e reformular as informações de caráter técnico para leitores com interesses e objetivos diversos na compreensão dos acontecimentos científicos. Essa aproximação entre as esferas científica e cotidiana determina um deslocamento social da ciência, uma vez que ela parte das comunidades discursivas onde a princípio é produzida, ou seja, das universidades, dos institutos de pesquisa, dentre outros, para o público em geral.

Os distintos recursos linguístico-discursivos como expansão, redução e variação utilizados para recontextualizar as informações sobre ciência, com o objetivo de garantir a

\footnotetext{
1 "Como cualquier otra forma discursiva, la divulgación no es una práctica objetiva, neutra o desvinculada de personas e intereses; por el contrario, es el resultado de la negociación entre sus interlocutores." (CASSANY et al., 2000, p. 77, tradução nossa).
} 


\section{Revista do SELL}

v. 6 , no. 3

ISSN: $1983-3873$

compreensão do público em geral e, consequentemente, impulsionar a efetiva participação cidadã nas transformações sociais, culturais, políticas, ambientais, econômicas, industriais, éticas e jurídicas proporcionadas pelos diversos avanços tecnológicos, são muitos e variados e têm uma importância vital, já que a utilização dos procedimentos mais apropriados e adequados dependerá do ciclo comunicativo que permitirá o diálogo entre ciência, tecnologia e sociedade. Portanto, a função do jornalista científico é saber integrar os novos conhecimentos no processo de construção cultural que ocorre no âmbito da vida cotidiana (CALSAMIGLIA, 1997).

Assim, a atividade de divulgar informações de caráter científico na mídia impressa apresenta-se a partir de uma variedade de estratégias divulgativas (CASSANY e MARTÍ, 1998; CATALDI, 2007b; 2008; 2011) que compreendem um vasto espectro que vai desde a definição, por um lado, até a metáfora no outro, passando pela aposição explicativa, a paráfrase, a denominação, a exemplificação, a comparação, a analogia, dentre outras. É muito provável que em um mesmo texto se tome, várias vezes e em momentos distintos, decisões diferentes sobre se usar ou não um determinado conceito e com que recursos expressivos. Cada procedimento discursivo contribui de forma específica para a difusão da informação de caráter científico. Segundo Gomes (2007), cada escolha sintática, semântica ou lexical é determinada pela busca da forma mais adequada de se obter o efeito de sentido e a compreensibilidade desejados.

Nesse processo de divulgação da informação sobre ciência, para que haja uma aproximação entre o conhecimento científico e o conhecimento do público em geral, fazse necessário que os jornalistas atuem como mediadores. Segundo Van Dijk (2011),

(...) tanto os cientistas como o público em geral pertencem a distintas comunidades de conhecimento. Esta é uma das razões pelas quais o público em geral não pode compreender a maior parte do discurso científico. No entanto, alguns jornalistas, de fato, podem entendê-lo e, dessa forma, são capazes de atuar como mediadores quando escrevem sobre a ciência de maneira inteligível para o público geral (VAN DIJK, 2011, p. 19).

É de suma importância destacar que além dos jornalistas, conforme Van Dijk (2011) pontua, alguns cientistas também podem atuar como mediadores, a partir do momento em que esses optam por transmitir, de maneira inteligível para o público em geral, suas descobertas. 


\section{Revista do SELL}

v. 6 , no. 3

ISSN: $1983-3873$

Realizar, portanto, uma análise discursiva no texto "Por que 2012?" que foi veiculado pela revista Superinteressante acerca do Fim do Mundo com a finalidade de se identificar os procedimentos linguístico-discursivos e as estratégias divulgativas utilizadas pela revista em pauta é bastante significativo no âmbito da Análise do Discurso de Divulgação Científica.

\section{O Tema "Apocalipse místico" na Superinteressante}

O capítulo 1 da edição especial da revista Superinteressante denominado "Apocalipse místico" é composto por dois textos: "Por que 2012?" e "O fim do mundo nas religiões". O primeiro deles foi escolhido para compor o corpus do presente artigo devido à temática por ele abordada: o Fim do Mundo Maia.

Nesse texto, José Lopes discorre a respeito da crença de que o Fim do Mundo ocorreria no dia 21 de dezembro de 2012, data que ficou conhecida como Apocalipse Maia. Segundo ele, o mais provável é que a ideia de uma "Profecia Maia" tenha surgido a partir de uma leitura equivocada dos registros deixados pela Civilização Maia. Para entender isso, Lopes afirma que é relevante buscar compreender o sistema matemático que eles empregavam para contar o tempo naquela época.

O título do capítulo - "Apocalipse místico" - fornece uma pista para o leitor, a partir do termo "místico", de que a abordagem do tema será sobre o Fim do Mundo na perspectiva da religiosidade, do divino e do sobrenatural, ou seja, o termo em pauta categoriza o tipo de apocalipse que será abordado no capítulo.

O título do texto - "Por que 2012?" - faz referência, de maneira implícita, a discursos anteriores sobre o Fim do Mundo Maia que, de acordo com a crença, seria no dia 21 de dezembro de 2012. A partir disso, ele questiona, instigando as pessoas a lerem o texto, pois a revista foi veiculada em novembro de 2012 e sabe-se que esse assunto gerou muita polêmica e curiosidade, principalmente no ano em questão. Além disso, esse tipo de questionamento provoca uma expectativa nos leitores de que o texto fornecerá explicações acerca dos motivos do Fim do Mundo ocorrer nessa data.

O título pode ser considerado uma pergunta retórica, uma vez que após essa indagação, no subtítulo, há a resposta: "A data vem do calendário maia. Esse antigo e avançado povo pré-colombiano tinha uma concepção cíclica do Cosmo e, de fato, o fim 


\section{Revista do SELL}

v. 6 , no. 3

ISSN: $1983-3873$

deste ano marcaria o encerramento de um ciclo. Mas seria mesmo o fim do mundo?".

Com relação ao lead, esse, primeiramente, revela a grande proporção que a temática em pauta adquiriu na sociedade:

(1) A esta altura do campeonato, você só não ouviu falar ainda do "Apocalipse maia" (...) se passou os últimos anos numa cabaninha no interior da Antártida, sem internet. O que tem de gente aterrorizada ou empolgada com a ideia não está no gibi.

Por meio desse trecho, percebe-se que esse assunto se tornou amplamente conhecido e divulgado, especialmente pela mídia, e provocou efeitos diversos nas pessoas, tais como, terror ou empolgação. Assim, a revista justifica a relevância dessa temática e, consequentemente, o motivo dela estar sendo veiculada na mesma.

Posteriormente, o lead fornece um resumo geral da informação que será discutida no texto, revelando a possibilidade de que a "profecia maia" tenha surgido de uma leitura equivocada dos registros deixados por essa civilização. A partir disso, ressalta a necessidade de se compreender o sistema matemático que eles usavam para contar o tempo, o qual é discutido mais detalhadamente no decorrer da reportagem.

A linguagem do texto é revestida do registro informal, como pode ser observado nos seguintes trechos:

(2) A esta altura do campeonato, você só não ouviu falar ainda do "Apocalipse maia" (...) se passou os últimos anos numa cabaninha no interior da Antártida, sem internet. O que tem de gente aterrorizada ou empolgada com a ideia não está no gibi.

(3) (...) basta se concentrar nessa unidade temporal grandalhona, o b'ak'tun.

(4) As ideias de Coe foram popularizadas - e um bocado forçadas - por uma série de escritores místicos dos anos 1970 para cá e, claro, pela internet - fonte inesgotável de boataria esotérica.

Em relação à utilização da linguagem informal, há diversos registros da linguagem oral no texto, inseridos na busca de se dialogar com o leitor:

(5) A primeira coisa a levar em conta quando se consideram os calendários maias (sim, eram vários, criados para propósitos diferentes e estruturados de maneira distinta) é que a base matemática dessa cultura não era o número 10, como acontece no Ocidente, mas o número 20. 


\section{Revista do SELL}

v. 6 , no. 3

ISSN: $1983-3873$

(6) Nele, cada data é formada associando-se um número de 1 a 13 a cada um dos 20 "dias da semana" - daí o número de dias do "ano santo" já que $13 \times 20=260$. (As datas eram escritas numa forma que combinava uma contagem até 13 e o nome do dia: 1lmix', 2 lk', 3 Ak'b'al e por aí vai).

(7) (...) ele era formado por 18 meses de 20 dias cada um (continue com as contas aí: 18 × $20=360$ ), mais uma adição de cinco dias "sem mês" para completar os 365 dias do ano.

Assim, observa-se a intenção do jornalista em estabelecer uma cumplicidade com o leitor, como em (5), por meio do termo "sim", confirmando o que esse estivesse pensando, ou como acontece em (6) e (7) através de uma tentativa de se esclarecer uma informação para o leitor, fazendo uso de expressões informais, como "e por aí vai" e "continue com as contas aí", respectivamente.

Concernente à abordagem científica evidenciada no texto, percebe-se uma preocupação em fornecer ao leitor explicações e informações objetivas, como pode ser observado no seguinte trecho:

(8) A Contagem Longa tinha uma sequência de números, mais ou menos como a casa das unidades, das dezenas e das centenas num número como 231. A casa das unidades correspondia ao número de dias (k'in); 20 deles perfazem um uinal ("mês"); um grupo de 18 uinal dá um tun ("ano"); junte 20 tun e você tem um k'atun, os quais, também agrupados em conjuntos de 20, formam um b'ak'tun (esse (sic) última unidade dá 144 mil dias, ou 394 anos dos nossos).

Em (8), explica-se o que seria a Contagem Longa e destacam-se informações objetivas, por meio de números e unidades de medida, como, por exemplo, em: "um grupo de 18 uinal dá um tun ("ano"); junte 20 tun e você tem um k'atun".

A seguir, serão apresentados os procedimentos linguístico-discursivos de expansão, redução e variação identificados na reportagem analisada.

\section{PROCEDIMENTOS LINGUÍSTICO-DISCURSIVOS DE EXPANSÃO, REDUÇÃO E VARIAÇÃO}

\section{a) Procedimento de expansão}

O procedimento linguístico-discursivo de expansão, que tem como finalidade discursiva substituir um termo e/ou expressão por outro de mesmo valor semântico, 


\section{Revista do SELL}

v. 6 , no. 3

ISSN: $1983-3873$

mencionar conhecimentos compartilhados pelos leitores, explicitar uma nova informação que, de forma implícita, já havia sido mencionada no texto, ocorre no texto intitulado "Por que 2012?", por meio das seguintes estratégias divulgativas: explicação, analogia, definição, argumento de autoridade e pergunta retórica.

\section{a1) Explicação}

Gomes (2007, p. 170) ressalta que "ter competência explicativa deveria ser requisito fundamental para quem produz textos de divulgação científica". A estratégia divulgativa de explicação pode ser identificada em alguns momentos no texto supracitado, a partir da utilização de travessão (9), dois pontos (10), vírgulas explicativas (11) ou até mesmo de parênteses (12):

(9) Há uma série de problemas com essa hipótese, no entanto. Um deles é o fato de que em nenhum texto maia há uma descrição de que diabos aconteceria quando ocorresse a chegada de $13 b_{i} a k_{i}$ tun desta vez nenhuma previsão de dilúvio, tempestade de fogo, sumiço do Sol e da Lua etc., essas coisas tão comuns em narrativas apocalípticas mundo afora.

(10) E aqui é que finalmente aparece uma pista da suposta data do Apocalipse: a criação atual parece ter começado quanto (sic) a anterior completou 13 b'ak'tun.

(11) A combinação desses números gera o primeiro elemento importante dos calendários maias, o "ano santo" de 260 dias.

(12) A esta altura do campeonato, você só não ouviu falar ainda do "Apocalipse maia" (que supostamente vai acabar com a Terra em 21 de dezembro deste ano) se passou os últimos anos numa cabaninha no interior da Antártida, sem internet.

Em (9) explica-se, através de uma gradação, que não há registros de que os maias previram dilúvios, tempestades de fogo, desaparecimento do Sol e da Lua. No excerto (10), se esclarece qual é a pista da suposta data do Apocalipse. Em (11), se explicita qual é o primeiro elemento importante do Calendário Maia e, por último, em (12), se explica brevemente o que seria o Apocalipse maia. É notório que todas essas explicações adicionam variadas informações acerca do "Apocalipse maia". 


\section{Revista do SELL}

v. 6 , no. 3

ISSN: $1983-3873$

\section{a2) Analogia}

Analogia significa comparação ou relação entre várias informações e conceitos. Parte-se do conhecimento prévio do leitor e compara-se esse conhecimento à nova informação introduzida no texto divulgado. A estratégia divulgativa de analogia é utilizada no texto em questão para se referir ao Sistema matemático e ao Calendário maia:

(13) (...) a base matemática dessa cultura não era o número 10 , como acontece no Ocidente, mas o número 20.

(14) A Contagem Longa, como acontece com o calendário cristão, tem um momento de início, que pode ser calculado (...).

Em (13), elucida-se que a base matemática da cultura maia era o número $20 \mathrm{e}$, para que essa informação seja melhor compreendida pelo leitor leigo, compara-se a base matemática desse povo com a do Ocidente, que é o número 10. No trecho (14), estabelece-se uma semelhança entre a Contagem Longa e o calendário cristão, já que esse é mais conhecido pelo público leitor da revista em pauta, facilitando, portanto, o entendimento da informação.

\section{a3) Definição}

A estratégia divulgativa de definição é um importante procedimento léxicosemântico utilizado nos textos de divulgação científica (CATALDI, 2008) e pode ser observada nos trechos que buscam definir sistemas que eram usados pelos maias para a contagem de tempo:

(15) Foi pensando nisso que os maias desenvolveram a chamada Contagem Longa, um sistema de datação linear, e não cíclico, como os outros, embora também usasse as informações deles. A Contagem Longa tinha uma sequência de números, mais ou menos como a casa das unidades, das dezenas e das centenas num número como 231. A casa das unidades correspondia ao número de dias (k'in); 20 deles perfazem um uinal ("mês"); um grupo de 18 uinal dá um tun ("ano"); junte 20 tun e você tem um $k_{i}$ atun, os quais, também agrupados em conjuntos de 20 , formam um b'ak'tun(...).

(16) Ao mesmo tempo, os maias também possuíam um calendário que tentava acompanhar o tempo que leva para a Terra dar uma volta 


\section{Revista do SELL}

v. 6 , no. 3

ISSN: $1983-3873$

completa em torno do Sol. Conhecido como Haab $i$, ele era formado por 18 meses de 20 dias cada um.

A partir desses excertos, percebe-se que em (15) conceitua-se "Contagem Longa" e em (16) "Haabi". Além disso, no texto em análise, foi identificada uma definição em um argumento de autoridade, como pode ser percebido no seguinte trecho:

(17) E o exemplar mais antigo de um calendário maia já descoberto não faz nenhuma referência ao suposto fim do mundo. São tabelas astronômicas achadas na antiga cidade de Xultun, na Guatemala, pela equipe de William Saturno, da Universidade de Boston, que provavelmente datam do ano 813 da Era Cristã.

Em (17), define-se o exemplar mais antigo de um calendário maia já descoberto e, ao mesmo tempo, comunica-se por quem ele foi encontrado - pela equipe de William Saturno, da Universidade de Boston. Ademais, explicita-se a procedência das pessoas que o encontraram, a fim de dar ainda mais credibilidade à informação que está sendo divulgada. Ao se utilizar de definições claras e objetivas, o jornalista possibilita que o leitor compreenda de forma significativa o conhecimento que está sendo abordado.

\section{a4) Argumento de autoridade}

Ferrero (2011, p. 94) destaca que "o discurso que se cita é diferente do discurso original, do qual procedem as palavras citadas. Essa recontextualização do discurso transforma as palavras ditas, sua forma e seu conteúdo". Assim, o grau de credibilidade que se atribui aos cientistas é determinado pela forma como os jornalistas evidenciam os seus posicionamentos. No decorrer do texto, são utilizados alguns argumentos de autoridade de cientistas para discutir se o Fim do Mundo realmente ocorreria no dia 21 de dezembro de 2012, como pode ser percebido nos seguintes trechos:

(18) Isso levou alguns especialistas a acreditar que, para os maias, a "Quarta Era" do mundo também duraria 13 b'ak'tun, o que acaba nos levando à famigerada data de 21 de dezembro de 2012 no calendário que usamos no Ocidente, uma interpretação proposta originalmente por Michael Coe, um importante especialista americano na cultura dos antigos maias. As ideias de Coe foram popularizadas - e um bocado forçadas por uma série de escritores místicos dos anos 1970 para cá e, claro, pela internet - fonte inesgotável de boataria esotérica. 


\section{Revista do SELL}

v. 6 , no. 3

ISSN: $1983-3873$

(19) São tabelas astronômicas achadas na antiga cidade de Xultun, na Guatemala, pela equipe de William Saturno, da Universidade de Boston, que provavelmente datam do ano 813 da Era Cristã. Saturno, que publicou sua descoberta na revista especializada Science, conta que os ciclos maias ali registrados se estendiam por 7 mil anos no futuro, muito depois de 2012. "Para eles, nada mudaria no Universo" depois da suposta data fatídica, afirma o pesquisador.

Em (18), o jornalista demonstra que até especialistas na cultura maia, como Michael Coe, acreditaram que para essa civilização o mundo acabaria no dia 21 de dezembro de 2012, visto que seria o fim do $13^{\circ}$ baktun. Já em (19), o jornalista afirma que, conforme William Saturno, os ciclos maias registrados se estenderiam por 7 mil anos no futuro, ou seja, o mundo não acabaria no dia 21 de dezembro de 2012. Percebe-se, assim, a apresentação de diferentes posicionamentos sobre o tema em questão, o que evidencia uma orientação argumentativa da informação que se divulga.

\section{a5) Pergunta retórica}

Como estratégia para expansão da informação, o jornalista faz uma pergunta e, posteriormente, a responde. Por meio desse procedimento retórico-discursivo, fica garantida a progressão de informações no texto e, além disso, facilita a compreensão, já que chama o leitor dialogicamente para participar da construção do conhecimento que está sendo divulgado.

(20) Ora, e quanto às coisas que ocorreram antes desse "ano zero" maia? Conforme ocorria com outras civilizações antigas, os maias tinham uma visão cíclica sobre a natureza do tempo. Embora o dia 31 de agosto do ano 3114 a.C. fosse considerado a data da criação do mundo, narrativas mitológicas, como o livro Popol Vuh (escrito, é bom lembrar, depois da chegada dos espanhóis), afirmam que três outras criações tinham existido antes da nossa, a quarta - basicamente ensaios dos deuses que não deram muito certo. E aqui é que finalmente aparece uma pista da suposta data do Apocalipse: a criação atual parece ter começado quanto (sic) a anterior completou 13 b'ak'tun.

Percebe-se que em (20) o jornalista questiona: "Ora, e quanto às coisas que ocorreram antes desse 'ano zero' maia?" Em seguida, ele fornece a resposta: "narrativas mitológicas (...) afirmam que três outras criações tinham existido antes da nossa".

\section{b) Procedimento de redução}




\section{Revista do SELL}

v. 6 , no. 3

ISSN: $1983-3873$

O procedimento linguístico-discursivo de redução, utilizado para suprimir as informações de caráter mais especializado, que por diversos motivos não são relevantes, necessárias e convenientes de serem divulgadas, ocorre poucas vezes no texto "Por que 2012?". No trecho a seguir, esse procedimento ocorre por supressão da informação:

(21) Embora o dia 31 de agosto do ano 3114 a.C. fosse considerado a data da criação do mundo, narrativas mitológicas, como o livro Popol Vuh (escrito, é bom lembrar, depois da chegada dos espanhóis), afirmam que três outras criações tinham existido antes da nossa, a quarta basicamente ensaios dos deuses que não deram muito certo.

No excerto (21), possivelmente a informação acerca de quais seriam as três criações que existiram antes da atual não foi considerada relevante ou conveniente para ser divulgada, por isso, foi suprimida.

Já no trecho (22) a seguir, a redução ocorre por condensação, pois é fornecida uma informação superficial e resumida sobre o que é feito para localizar determinado dia no calendário, sendo a informação, dessa maneira, condensada:

(22) Para localizar determinado dia no calendário, os maias juntavam a data do calendário sagrado e a do Haab.

\section{c) Procedimento de variação}

A fim de adequar a linguagem para um público não especialista e de produzir um texto mais coeso, a revista Superinteressante recorre ao procedimento discursivo de variação, como uma importante estratégia léxico-semântica para se referir ao termo divulgado. Esse procedimento é utilizado diversas vezes ao se referir, por exemplo, aos "maias", contudo, mesmo assim, esse termo aparece dez vezes no texto analisado. Em (23), observa-se um trecho no qual esse vocábulo é utilizado:

(23) (...) os antigos maias teriam sido capazes de apontar com precisão o fim de uma era do Cosmo, correlacionando esse período com outras eras de criação e destruição estabelecidas por sua cultura.

Pode-se observar nos trechos seguintes as variações que foram empregadas para designar os "maias": 


\section{Revista do SELL}

v. 6 , no. 3

ISSN: $1983-3873$

(24) A data vem do calendário maia. Esse antigo e avançado povo précolombiano tinha uma concepção cíclica do Cosmo e, de fato, o fim deste ano marcaria o encerramento de um ciclo.

(25) Tudo muito interessante, sem dúvida, mas o mais provável é que a ideia de uma "profecia maia" tenha surgido de uma leitura equivocada dos registros deixados pela civilização da América Central.

(26) A primeira coisa a levar em conta quando se consideram os calendários maias (sim, eram vários, criados para propósitos diferentes e estruturados de maneira distinta) é que a base matemática dessa cultura não era o número 10, como acontece no Ocidente, mas o número 20.

(27) Esses sujeitos faziam construções de pedra que deviam durar para a posteridade - tanto que algumas ainda estão lá séculos depois, como sabemos - e queriam dizer exatamente para seus descendentes longínquos quando tinham mandado construir aquela pirâmide sensacional.

(28) A Contagem Longa, como acontece com o calendário cristão, tem um momento de início, que pode ser calculado: equivaleria ao dia 31 de agosto do ano 3114 a.C. - época em que, é bom lembrar, a civilização maia nem tinha surgido ainda (o consenso entre os arqueólogos é que ela se organizou originalmente em torno de 2000 a.C.).

A partir dessa descrição, o quadro abaixo explicita as variações que ocorreram para designar os "maias":

\begin{tabular}{|c|}
\hline Maias \\
\hline povo pré-colombiano \\
\hline civilização da América Central \\
\hline dessa cultura \\
\hline esses sujeitos \\
Quadro 1: variações encontradas no texto "Por que 2012?" para o termo "maias".
\end{tabular}

Outro termo por meio do qual pode-se perceber a utilização do procedimento linguístico-discursivo da variação é o "fim do mundo":

(29) Mas seria mesmo o fim do mundo? 


\section{Revista do SELL}

v. 6 , no. 3

ISSN: $1983-3873$

(30) A esta altura do campeonato, você só não ouviu falar ainda do "Apocalipse maia" (...) se passou os últimos anos numa cabaninha no interior da Antártida, sem internet.

(31) (...) os antigos maias teriam sido capazes de apontar com precisão o fim de uma era do Cosmo, correlacionando esse período com outras eras de criação e destruição estabelecidas por sua cultura.

(32) E aqui é que finalmente aparece uma pista da suposta data do Apocalipse: a criação atual parece ter começado quanto (sic) a anterior completou 13 b'ak'tun.

O quadro abaixo mostra as variações em relação à expressão "fim do mundo":

\begin{tabular}{|c|}
\hline fim do mundo \\
\hline Apocalipse maia \\
\hline fim de uma era do Cosmo \\
\hline Apocalipse \\
\hline
\end{tabular}

Quadro 2: variações encontradas no texto "Por que 2012?" para a expressão "fim do mundo".

\section{SÍNTESE DA ANÁLISE}

Percebe-se, por meio da análise realizada, que o texto "Por que 2012?" publicado na revista Superinteressante, em novembro de 2012, busca atrair a atenção do leitor, a começar pelo título, que resgata um discurso anterior e polêmico de que o mundo acabaria em 21 de dezembro de 2012. Posteriormente, no subtítulo, explica-se de onde vem a crença nessa data e, no final, há um questionamento intrigante: "Mas seria mesmo o fim do mundo?". Tudo isso faz com que o leitor tenha vontade de ler o texto na esperança de obter respostas a esses questionamentos.

O texto apresenta um caráter explicativo, já que há a utilização de vários procedimentos linguístico-discursivos de expansão. Por outro lado, há poucos procedimentos de redução, como a supressão e a condensação de informações procedentes do âmbito científico, pois nota-se que o jornalista José Lopes quis discorrer detalhadamente sobre o sistema matemático que os maias empregavam para contar o tempo, a fim de fazer o leitor compreender o mesmo e de demonstrar que a crença de 


\section{Revista do SELL}

v. 6 , no. 3

ISSN: $1983-3873$

que o fim do mundo maia ocorreria no dia 21 de dezembro de 2012 se baseou em um erro de interpretação.

Em relação ao procedimento de variação, a denominação que mais se destacou foi "esses sujeitos", para se referir aos "maias". Contudo, como se trata de uma revista voltada para o público jovem, o uso dessa expressão um tanto quanto informal pode promover uma aproximação desse público com o texto. Constata-se, assim, que todos os procedimentos linguístico-discursivos utilizados auxiliam de forma bastante significativa na compreensão do leitor, já que minimizam a distância entre o conhecimento técnico e científico do conhecimento social e cotidiano.

\section{CONSIDERAÇÕES FINAIS}

Pautando-se no quadro teórico-metodológico referente à Análise do Discurso de Divulgação Científica, esse trabalho propôs investigar o tratamento linguístico-discursivo conferido às informações publicadas em uma reportagem contida na revista Superinteressante, edição especial de novembro de 2012, durante a polêmica suscitada pela profecia da Civilização Maia em relação ao Fim do Mundo, considerando a linha editorial da mídia em questão.

Assim, foi descrito e analisado como ocorre o processo de recontextualização da informação científica em informação divulgada por meio dos procedimentos linguísticodiscursivos de expansão, redução e variação e das estratégias divulgativas.

Constata-se que a reportagem analisada é um texto de divulgação mais explicativo do que conceitual, já que faz-se um amplo uso da estratégia divulgativa da explicação e pouco se utiliza da definição. Como o público da revista é, em sua maioria, jovem, é mais significativo para esse leitor explicar do que definir. Ademais, por se tratar de um texto de divulgação científica, foram mencionados alguns argumentos de autoridade que legitimaram as informações procedentes do âmbito científico.

Considerando que o discurso de divulgação científica é um campo de estudo fértil concernente ao fornecimento de dados para pesquisa e também reconhecendo a relevância das práticas discursivas que ocorrem nesse âmbito, é sempre importante observar se os meios de comunicação partem de uma especulação para neutralizá-la ou aumentar a polêmica. Nesse caso, a revista Superinteressante, a partir da publicação em 


\section{Revista do SELL}

v. 6 , no. 3

ISSN: $1983-3873$

novembro de 2012 dessa edição especial, teve como objetivo esclarecer o seu leitor em relação às polêmicas suscitadas referentes ao Fim do Mundo profetizado pela Civilização Maia, possibilitando que essa discussão fosse realmente realizada.

\section{REFERÊNCIAS}

CALSAMIGLIA, Helena. Divulgar: itinerários discursivos del saber. Quark, Barcelona: Observatorio de la Comunicación Científica, Universitat Pompeu Fabra, n.7, 1997, p. 9-18. . (Ed.). Popularization discourse. Discourse Studies, London: Sage, v. 5, n. 2, 2003, p. 139-146.

CALSAMIGLIA, H. (Coord.); BONILLA, S.; CASSANY, D.; LÓPEZ, C.; MARTÍ, J. Análisis discursivo de la divulgación científica. Lengua, Discurso, Texto (I Simposio Internacional de Análisis del Discurso). Madrid, v. II, 2001, p. 2639-2646.

CATALDI, Cristiane. Los transgénicos en la prensa española: una propuesta de análisis discursivo. Tese (Doutorado). Barcelona: Universitat Pompeu Fabra, 2003. 409p. . A divulgação da ciência na mídia impressa: um enfoque discursivo. In: GOMES, M. C. A.; MELO, M. S. S.; CATALDI, C. (Org.). Gênero discursivo, mídia e identidade. Viçosa- MG: Ed. UFV, 2007a, p. 155-164.

. Análise discursiva da denominação utilizada na mídia impressa para representar e divulgar o conhecimento sobre planta transgênica. In: GOMES, M. C. A.; MELO, M. S. S.; CATALDI, C. (Org.) Gênero discursivo, mídia e identidade. ViçosaMG: Ed. UFV, 2007b, p. 193-209.

A definição utilizada como estratégia divulgativa sobre transgênico na mídia impressa. Vertentes, São João Del-Rei: UFSJ, n. 32, 2008, p. 256-265.

O discurso sobre ciência: os transgênicos em foco na mídia impressa. In: GOMES, Maria Carmen Aires; CATALDI, Cristiane; MELO, Mônica Santos de Souza (Org.). Estudos discursivos em foco: práticas de pesquisa sob múltiplos olhares. Viçosa - MG: Ed. UFV, 2011, p. 71-92.

CASSANY, Daniel et al. La transformación divulgativa de redes conceptuales científicas. Hipótesis, modelo y estrategias. Discurso y sociedad, v. 2, n. 2, 2000, p. 73-103.

CASSANY, D.; MARTí, J. Estrategias divulgativas del concepto prión. Quark, Barcelona: Observatorio de la Comunicación Científica, Universitat Pompeu Fabra, n. 12, p. 56-66, 1998.

CIAPUSCIO, G. Linguística y divulgación de ciência. Quark, Barcelona: Observatorio de la Comunicación Científica, Universitat Pompeu Fabra, n.7, 1997, p. 19-28. 
FERRERO, C. L. A mescla de vozes em artigos jornalísticos: o caso da "Vaca Louca". In: GOMES, M. C. A.; CATALDI, C. MELO, M. S. S. (Org.). Estudos discursivos em foco: práticas de pesquisa sob múltiplos olhares. Viçosa- MG: Ed. UFV, 2011, p. 93-110.

GOMES, I. M. A. M. O texto e o discurso na revista Ciência Hoje. In: GOMES, M. C. A.; MELO, M. S. S.; CATALDI, C. (Org.). Gênero discursivo, mídia e identidade. Viçosa MG: Ed. UFV, 2007, p. 165-191.

SANT'ANA, Maíra Ferreira. A origem e o fim do mundo: análise discursiva de textos de divulgação científica na Superinteressante. Dissertação (Mestrado). Viçosa: MG, 2014. 176p.

VAN DIJK, T. A. Por uma teoria da comunicação científica: discurso, conhecimento, contexto e compreensão da sociedade. In: GOMES, M. C. A.; CATALDI, C. MELO, M. S. S. (Org.). Estudos discursivos em foco: práticas de pesquisa sob múltiplos olhares. Viçosa- MG: Ed. UFV, 2011, p. 19-40. 